\title{
Impact and Scope of Intelligent Textiles in Health Care
}

\section{Pravin Shende* and Anvi Desai}

Shobhaben Pratapbhai Patel School of Pharmacy and Technology Management, SVKM's NMIMS, Vile Parle (W), Mumbai, India

\begin{abstract}
The last few years have shown tremendous development in the field of science and technology, nanoengineering, electronic devices, wireless communications, etc. Now-a-days researchers are venturing new ideas and possibilities into various arrays of human life especially healthcare management using medical textiles. It is one of the most rapidly evolving area due to advance developments in applications of textile materials like chitosan-, $\beta$-cyclodextrinfullerene- and alginate-based textiles. This article also explores e-textiles (sensors) in the medical field, progress in effective wound care management, textile-based medical implantable devices and applications of intelligent textiles for various surgical products. This review article focuses on advancements of smart textiles and their applications in the healthcare industry.
\end{abstract}

Keywords: Textile; Sensors; Wound care; Surgical products

\section{Introduction}

A country's economic capability and the quality of its population's lifestyle depend up-on the competency of the scientists and researchers to innovate and establish socially relevant creations. Ever since the creation of life on earth, continuous efforts are being made to improve the quality of life andwith marvellous creations of science, people have successfully been able to enrich their lifestyles. The average lifespan of humans has increased due to developments in health and nutrition. The last decade has shown tremendous growth in the development of nanotechnology, wireless communication technologies, information technologies and electronic devices. This has drawn the attention of scientists and researchers to visualize the denoting characteristics of these advancements and keep innovating for the betterment of the people. The world is significantly rising towards a new generation of intelligent and smart discoveries; creativity and problem-solving techniques and amongst from such paradigms, the 'smart and intelligent textiles' [1].

Medical textiles are a rewarding and an exciting area having enormous possibility to re-model people's daily lives. Use of textiles in healthcare industry goes back to centuries before Christ. Use of cotton, silk and flax etc., for a variety of purposes like wound dressings, sutures, dates back to 5000 BC. References of textile applications in a medical field in preceding civilizations, like Persian, Roman, Egyptian, Chinese and Asians are superfluous in many works of literature [2]. The use of textiles in medical applications remained unchanged until the late 19th century, when an in-depth understanding of physical properties of materials, in general, led to increased interest in building blocks and internal special arrangements of natural fibers. The possible modifications can be done to alter their chemical, physical, mechanical and morphological characteristics. For example, Mercerization is a process by which characteristics of cotton are altered so that it becomes softer, stronger and lustrous in appearance [3]. During the 1890s, artificial silk popularly known as 'Rayon' or 'Viscose' was developed [4]. This resulted in the use of wood pulp as the primary source of pure cellulose. The manual manipulation of pure cellulose led to discovery of first ever artificial fibers and led to revolution of textile industry [4,5]. It is due to this revolution that textile materials began their journey of becoming 'specialized' [6].

The apparel and textile markets represent one of the most significant segments of the product manufacturing and world trade. Traditionally the textile industry was confined to the production of fibers, fabrics, yarns and textile goods. With innovation and technology, new possibilities in the textile industry are discovered and hence its applications are expanding. Innovations in textiles are in focus due to their multidisciplinary research in medicine and engineering and peculiar characteristics of textiles such as flexibility, light weight, dimensional variability and opportunities to attain specific properties via surface and structure modifications at different levels. Recently, a noticeable break-through has been achieved in enhancing the capabilities of textiles in response to environmental stimuli. Such textiles are called as smart textiles. These textiles possess the properties of conventional textiles and also carry additional functional values [7].

The potential of the market for medical textile devices and healthcare is increasing rapidly. The market medical textiles are worth US $\$ 7$ billion and comprise about $10 \%$ of the market of technical textiles in Europe [8]. The European market absorbs 100000 tons of fibers per year and is expanding in volume by $3 \%-4 \%$ per annum. The world-wide medical device sector was found out to be valued at US $\$ 100$ billion, out of which US $\$ 43$ billion was produced from the US market [8]. Western Europe comes second and comprises for nearly $25 \%$ of the global medical device market. The National Health Services (NHS), constituting about $80 \%$ of healthcare expenses, in spite of lesser private sectors. It is forecasted that the share of medical textiles and hygiene would be $12 \%$ of the overall technical textiles market and will constitute for US \$4.1 billion [8]. Medical textiles in India are still at the introduction stage as compared to the global scenario [9]. The factors affecting the medical devices sector and healthcare market are as shown in Figure 1.

\section{Materials and Methods}

\section{Smart medical textiles}

'Smart Textiles' corresponds to a wide arena of products as well as the studies which enhance the usefulness and functionality of conventional

${ }^{*}$ Corresponding author: Pravin Shende, Shobhaben Pratapbhai Patel School of Pharmacy and Technology Management, SVKM's NMIMS, Vile Parle (W), Mumbai, India, Tel: +91-22-42332000; Fax: +91-2226185422; E-mail: shendepravin94@gmail.com

Received September 22, 2017; Accepted November 17, 2017; Published November 27, 2017

Citation: Shende P, Desai A (2017) Impact and Scope of Intelligent Textiles in Health Care. J Bioequiv Availab 9: 577-584. doi: 10.4172/jbb.1000364

Copyright: $\odot 2017$ Shende $P$, et al. This is an open-access article distributed under the terms of the Creative Commons Attribution License, which permits unrestricted use, distribution, and reproduction in any medium, provided the original author and source are credited. 


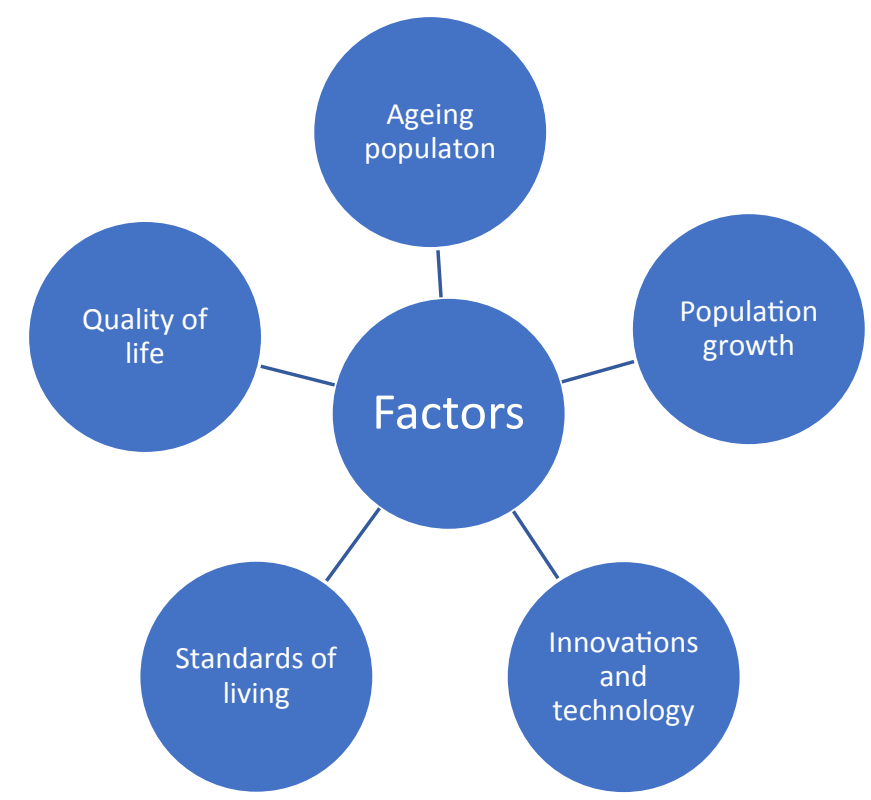

Figure 1: Factors affecting the medical devices sector and healthcare market.

fabrics. They defined as textile products such as filaments and fibers, yarns along with knitted, woven or non-woven structures that connect with the environment or users [10]. These structures are able to sense the environmental conditions and stimuli $[11,12]$. Intelligent textiles on another hand are defined as textile structures that sense as well as respond to the environmental conditions and stimuli [11]. This stimuli or response could be mechanical, chemical, thermal, magnetic, electric or other sources [13]. According to their type of reaction, smart textiles can be categorized as passive smart materials, active smart materials and very smart materials [10-13].

1. Passive smart materials: These materials sense the environmental conditions and stimuli. They are known as sensors.

2. Active smart materials: These sense the environmental conditions and stimuli and reacts/responds to them. So, apart from sensor functions they also have actuation characters.

3. Very smart materials: These materials can sense and react to the environmental conditions and stimuli and adapt according to the prevailing circumstances.

As this is a newly developed field, there is no specific definition. Though, there are a number of other terms that are used to describe these materials such as e-textiles/electronic fabrics [14], photonic textiles [15], intelligent textiles, smart fabrics, etc. Smart textiles have found applications in a variety of multidisciplinary like automotive, civil, geotechnical, healthcare industry, etc. Their applications vary from in-vivo use in everyday activities to in-vitro applications [16].

The use of textile materials for healthcare and medical products ranges from simple gauze, scaffolds for tissue culturing, bandage materials to a variety of prosthesis for permanent body implants and much more. Textiles are omnipresent when it comes to the field of human hygiene and medical practice. Advanced medical textiles are developing due of their growth and improvement in the fields of bandaging and pressure garments, wound healing and controlled-release, implantable devices, medical devices, etc. Nano-fibers have found a broad application in scaffolds and tissue re-engineering because of their pore size distribution and large surface area. In recent years, nanotechnology is used to enhance the textile characteristics such as durability, breathability, softness, fire retardancy, water repellence, anti-microbial properties, etc. [17] Knitted and woven materials are extensively used in hernia meshes and making vascular grafts. Hollow fiber membranes are used in extracorporeal devices. For sutures and replacing tendons and ligaments, braided textiles are preferred [9].

\section{Textile slow release systems}

There are a number of routes of administrations for various dosage forms. Ointments, injections, pills, etc. are very common. They are useful in many situations, but in certain circumstances, other systems would be more suitable. When a drug is administered orally, they undergo hepatic metabolism also popularly known as the first pass effect before they enter the systemic circulation. As a result, the concentration of the drug available at the site of absorption decreases. Some of the drugs undergo metabolism in the GIT and the resulting metabolites might be toxic and dangerous [18]. When the dose is administered transdermally, the drug will circumvent the first pass effect. This will also allow reducing the amount of drug that is administered. Also, this route of administration is useful when the patient is unconscious, finds hard to swallow, neonates, etc. With modifications so as to allow prolonged drug release, transdermal injections are more preferable as compared to daily injections or pills. This section will discuss various promising systems which involve incorporation of smart textiles in order to obtain various textile slow release systems.

These systems include [19]:

I. Textiles containing cyclodextrins

II. Textiles containing ion-exchange fibers

III. Drug loaded hollow fibers

IV. Textiles containing fullerenes

V. Textiles containing aza-crown ethers 
These systems are particularly disturbed in terms of biocompatibility. It is defined as 'the ability of a substance to perform and give an appropriate host response during a specific application'. The elements included in biocompatibility are carcinogenicity, toxicity, mutagenicity, teratogenicity, etc. It also involves products biodegradability and biostability. It is important to make sure that these systems do not cause any secondary side effects that might affect the patient's other vital functions otherwise these slow re-lease systems would be of no use. The following information stated only involves qualitative considerations while comparing different textile slow release systems.

Textile containing cyclodextrins: The textiles that bear cyclodextrins constitute of conventional textile materials upon which the cyclodextrin molecules are grafted. Cyclodextrins can be defined as cyclic alpha-1,4 linked oligosaccharides, formed from a numerous of D-glucose units. There is alpha-, beta- and gamma- cyclodextrins as shown in Figure 2 [20]. They have a hydrophilic interior and hydrophobic exterior andthis makes them useful substances in complexation of drugs. The derivatives might be reactive (like cyclodextrin with mono-chlorotriazinyl (MCT) group), less hydrophilic (like because of lipophilic side chains like ethylhexyl glycidyl), more hydrophilic (due to hydrophilic side chains such as hydroxy-propyl) or ionic (due to ionic side chains like hydroxylpropyl trimethy ammonium chloride) [19].

Toxicity and carcinogenicity: Cyclodextrin containing textiles are not considered as harmful. In-depth studies of toxicity, teratogenicity, mutagenicity, carcinogenicity of certain cyclodextrins and their derivatives have been performed. These materials were potentially harmful only in extremely high concentration. There was no acute toxicity observed [21].

Biostability and biodegradability: For cyclodextrin containing textiles, the base material concerns the biostability and bio-degradability. Cotton and wool are biostable to a certain extent. Body substances do no immediately damages them but UV radiation, weather or attack of microorganisms are the primary causes of damage. Synthetic materials are comparatively more biostable. The cyclodextrins are readily biodegradable [19].

Textiles containing aza-crown ethers: Instead of cyclodextrins, another alternative is to attach aza-crown ethers to the textile materials. The literature on these systems is limited. Aza-crown ethers can be defined as neutral and macrocyclic polyether molecules where the oxygen atoms are completely or partially replaced by nitrogen as shown in Figure 3. Unlike cyclodextrins their basic form is 2D. Secondary amines are substituted. They can form stable complexes with transition metals. Their selectivity is affected due to factors like crown ring diameter, ion diameter, heteroatoms and the charge density of cations [19].

Toxicity and carcinogenicity: It has been discovered that the azacrown ethers are less toxic as compared to their crown ether equivalents because of reduced influence on the influx of potassium ions and efflux of sodium ions out of the cells. Complex ligands are less toxic than the non-complex ligands. It can be assumed that aza-crown ethers are toxic and carcinogenic within acceptable medical limits [22].

Biostability and biodegradability: The biodegradability depends on the base material. Incorporation of silver ions in aza-crown ethers led to enhancing long-term biostability.

Textiles containing fullerenes: Fullerenes are allotropic forms of carbon, they consist of only carbon atoms as shown in Figure 4.
Fullerenes act as a guest molecule and forms complex with macrocyclic ligands like cyclodextrins. They are olefinic, electrophilic and take part in several addition reactions. This is used for permanent fixation of
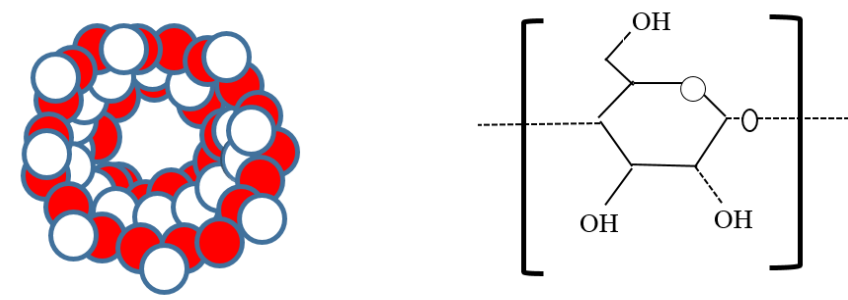

Figure 2: Structure of cyclodextrin.

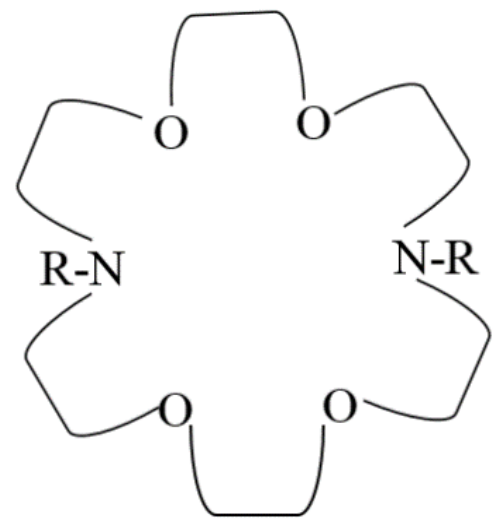

Figure 3: Structural formula of aza-crown ether

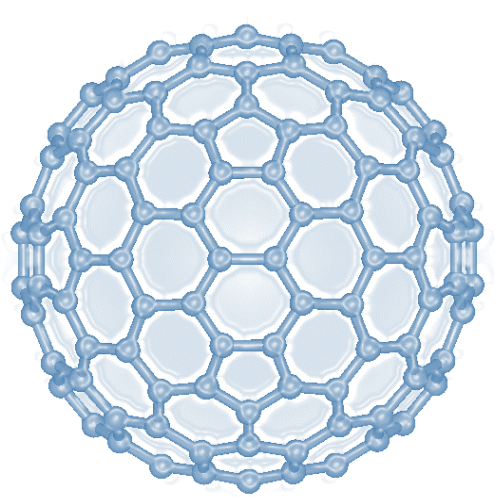

Figure 4: Structure of Fullerene.

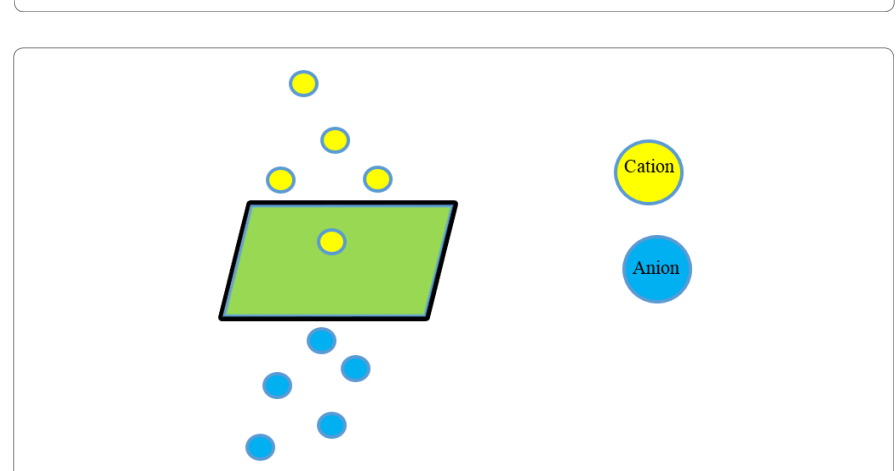

Figure 5: Process of ion-exchange. 
fullerenes to polymers like wool, PET and PA-6.6. All these materials contain amines.

Toxicity and carcinogenicity: They are not very toxic andfree fullerenes are used in other medical areas as well [23].

Biostability and biodegradability: No specific comments have been made.

Ion exchange fibers: Ion exchange fibers carry either positive or negative charge that is compensated by counter ions that are mobile and contain the opposite charge. The exchange is carried out by a diffusion process as shown in Figure 5. It is influenced by concentration gradients. The rate determining step is diffusion through the diffusion boundary layer. Ion-exchangers show specificity and this factor is used in controlling the exchanges. Commercial products of ion exchange fibers used for drug delivery are available such as 'Smopex' [18].

Toxicity and carcinogenicity: Toxicity and carcinogenicity depends upon the ion groups that are attached to the polymer units. Because of the bound nature, the danger from free ions is deleted. Usually, these ion groups are neutralized by suitable counter ion that can be a drug or an electrolyte.

Biodegradability and biostability: It is dependent upon the choice of the base material. The electrically charged groups will influence the bio stability and biodegradability. The change in the equilibrium of the fiber can result into a reactive system that is more prone to degradation [19].

Drug loaded hollow fibers: Hollow fibers are defined as small tubes that are filled with a drug. This fire consists of a permeable membrane that is used for controlling drug release as shown in Figure 6. These fibers have two advantages:

1. The surface area to volume ratio is high

2. The loading flexibility is high

This system comprises of a hollow tube filled with a drug solution or a liquid drug [24]. An alternative to this is a hollow fiber containing an ion exchange resin or crystals dispersed in a polymer core [25].

Toxicity and carcinogenicity: The material used as the matrix is usually a conventional material that is non-toxic and non-carcinogenic such as polyethylene or nylon. Thus, the possible toxic effect could come from the drug present in the hollow fiber. High doses of the drug are toxic and hence the release patterns should not give rise to such doses [19].

Biodegradability and biostability: It is dependent upon the material used to make the fiber wall.

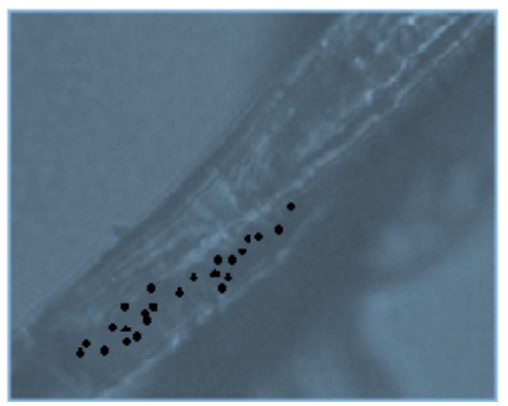

Figure 6: Drug loaded hollow fibers.

\section{E-textiles (sensors)}

Electronic textiles include smart health monitoring devices and sensors within clothing that can record and sense the basic bodily functions like respiration, body temperature, heart functioning, etc. and transmits this data through accessories like mobile phones, internet, etc. to health centres or hospitals or alert emergency units [26]. When completely adopted this approach will not only significantly reduce the costs but will also ensure that the patient's welfare is not compromised. The textile sensors for therapy uses and physiological monitoring vary in functions and applications, technology solutions and materials, their extent of integration, etc.

There are four general sensor structure categories [16]:

1. Fiber-based, when the sensor is a single yarn

2. Textile-integrated, when the textile carries the function of the carrier

3. Textile-structured, when all the components of the transducer are textile material

4. Textile-based, when textiles are a substrate or other nonsensitive, but an inseparable compound of a transducer

Textile sensors can be characterized according to their functions, applications and measurement unit. The structure of sensors is implemented by technologies like thin films, coating, lithography, inkjet printing, etc. [27]

Fiber optic technology is widely incorporated in smart textiles to form sensors. Fiber optic sensors can be categorized as [28]

1. Intrinsic sensors: The fiber optic comprises of a sensing element

2. Extrinsic sensors: The fiber optic is used as a mean to transport light

Fiber optics are widely used because they have good metrological properties like low sensitivity and low zero drift, large band width, good accuracy, immunity to electro-magnetic waves, etc. and because they are cheap, flexible, light weight, robust andthey can measure high strain values without causing any damage [29].

Another alternative of classifying fiber optic sensors is based on their working principle [30]:

1. Fiber Bragg Grating (FBG) Sensors: FBG sensors have a periodic perturbation of the refractive index along with fiber core length that is attained by exposing the core to an intense optical interference pattern.

2. Intensity Modulated Fiber Optic Sensors: They modulate light intensity. This light intensity is measured by means of a secondary element such as a photodiode in response to environmental stimuli.

\section{Various types of smart textiles available are:}

1. Sensing harness: In a sensing harness, the sensors are tactically placed for measurement of abdominal and thoracic movements caused due to breathing activity without corrupting signals or overlapping signals. These are designed such that they can be worn by both men and women. Certain places are kept free so as to facilitate resuscitation if necessary. For the thorax, FBG sensor was used that has high accuracy but low strain limit was used whereas for the abdomen, macro-bending sensors were used that have less accuracy [1].

2. Polyurethane sensor: A polyurethane paste is applied on a woven textile. This creates a high energy and smooth inter-surface layer. On 
top of this layer, a silver paste is painted to facilitate a conductive track. Silver pastes can also be applied to non-woven textiles for creating a wearable health monitoring device. Example: The National textile Centre of the North Carolina State University is working on a project that deals with 'Printing Electric Circuits on Non-woven Fabrics' and produce a prototype for physiological monitoring garments which measures ECG, respiration, heart rates and temperature [31].

3. Stretch sensitive sensors: They are used for monitoring and sensing body parameters, as the textile is in contact with a large area of the body. This allows simultaneous monitoring at several places in the body. These sensors are used for determining respirations, movement, blood pressure, heart rate, etc. [32]. The first approach was obtained by wiring gloves to the computer which takes inputs from user's hand gestures.

4. Temperature sensors: Temperature sensors that are based on smart textiles can provide temperature monitoring on skin surfaces as well as the near-body environment. This information can be used for enhancing patient's comfort, physiological assessment, monitoring wound healing, etc. The thermocouple is one of the simplest forms of temperature sensor implementation because of its structure. Working principle of these sensors depends upon the changes in metal electrical resistance pertaining to the temperature. FBG based temperature sensors are widely used due to their extreme sensitivity [16].

5. Respiration rate sensors: Optical fibers are widely used for such sensors. They are used for sleep monitoring andduring chronic respiratory disorders. They are often incorporated in combat clothing and can also be used to prevent sudden Infant Death Syndrome (SIDS) [33]. 'Respibelt' is a knitted belt device that is made from stainless steel yarn. It is worn around the thorax and it is capable of measuring thoracic changes in the perimeter, cross section, changes in inductance and resistance [34].

6. Humidity sensors: Moisture can be defined as absolute humidity indicative of an actual amount of vapor. Relative humidity is defined as the percentage of the vapor amount in the air at a particular temperature that compared to the amount of the vapor. Therefore, the textile material must be hydroscopic which means that it must easily absorb the vapours in the environment. The working principle of these sensors is based on measuring the changes in electrical impedance in the hygroscopic medium. Conductive textiles are most suitable for humidity sensor electrodes. Such sensors find wide applications in sweat rate monitoring, wound healing and ulcer prevention [16].

7. Sensors for $\mathrm{pH}$ level estimation: The $\mathrm{pH}$ level is an important indicator of the homeostasis. It is also an important aspect for mentoring sweating and wound healing. $\mathrm{pH}$ sensitive textiles are used for sweat collection and storage, wound healing monitoring, etc.

8. Pulse oximetry sensor: It's a non-invasive technique for estimation of arterial oxygen saturation in biological tissue. They measure the light absorption of the deoxygenated and oxygenated haemoglobin at two separate wavelengths in the near-infrared spectrum. Pulse oximetry sensors are used in recovery and emergency rooms, intensive care units, during anaesthesia, etc. [16].

\section{Smart textiles for wound care}

Wound management is very critical because infections caused due to improper care of wounds can be fatal for the patient's life. A wound is defined as a cut or a break in the continuity of a tissue that is caused due to an injury or an operation [35]. Wound healing. on the other hand, can be defined as the natural process of regenerating the epidermal and the dermal tissues that include a cascade of complex events that results into the revival of the affected tissue to a normal or a quasi-normal state found prior to the wound repair.

Wound healing passes through 4 phases [36]:

\section{Homeostasis}

2. Inflammation

3. Granulation tissue formation

\section{Remodelling}

These four phases overlap each other.

Wounds have been classified in many ways. This classification recognizes the extent of tissue loss, the kind of injury (thermal, chemical, sharp laceration, blunt contusion, etc.), foreign bodies, infection, structural injuries (fractures, vascular damage, ligament or ten-don injury, etc.)

\section{A basic classification of wounds is [37]:}

1. Wounds without tissue loss;

2. Wounds with tissue loss:

- Caused by due burns, trauma, and abrasion.

- Due to chronic ailments such as diabetic ulcer or venous stasis.

- Caused as a part of treatment such as skin grafting.

Based on the extent of injury, wounds can also be classified as:

1. Superficial wounds: involves only epidermis.

2. Wounds with partial thickness: involves epidermis and dermis.

3. Wounds with full thickness: involves epidermis, dermis and subcutaneous fat or deeper tissue.

\section{They are also categorized as:}

1. Acute wounds: minimal tissue loss and the healing proceeds with an orderly process

\section{Chronic wounds: wound healing fails an orderly process}

Traditionally, chlorhexidine, iodine, hydrogen peroxide was used as general antiseptics for wound management including irrigation, overall treatments. They have had their own advantages and disadvantages regarding the efficacy and suitability. Honey was also widely used for the treatment of wounds. Recently antimicrobial activities of honey have been discovered [38].

A wound dressing comprises of two layers.: The first layer is placed in contact with the wound and therefore the material used must be porous, bio-absorbable and adapted for acting as a scaffold for cell proliferation and attachment and the second layer usually comprises of an absorbent, gel forming material that acts as a barrier to cell adhesion and penetration [35]. Dressings are of two types: dry and wet. Traditions dressing systems were based on the principle of dry dressing however slowly it was discovered that wet dressing is much more preferable. Traditionally, the cotton gauze was used for dressing due to its strong absorption characteristics and soft handling. However, it was unable to maintain a moist environment that is required to facilitate faster wound healing. Studies show that in presence of the gauze, the moisture evaporates from the wound and adheres to the wound causing pain to the patient. It also requires frequent changing [39]. 
Depending upon the kind of materials used for preparing dressings, they can be categorized as [35]:

1. Biological dressings

2. Conventional dressings

3. Synthetic dressings

Within each category, they are further categorized as:

1. Primary dressing: Dressing that is in physical contact with the wound bed.

2. Secondary dressing: It covers primary dressing.

3. Island dressing: Dressing that is made with a central absorbent portion and is surrounded by an adhesive portion.

The ideal characteristics of smart textile based wound dressings must be as follows $[9,35]$ :

- It should cause no mechanical injury of the granulating wounds.

- It should have healing properties.

- Decrease adherence surface.

- Stable and spatial structure.

- Loose fibers should not get caught in the wound.

- Allow painless changing of the dressing.

- The wound secretion should be easily being able to penetrate into the absorbing wound dressing.

- The progress of wound healing should be uninterrupted i.e. only outer gauze compress is changed.

- Controls local temperature and $\mathrm{pH}$.

- Stimulates growth factors.

- Elastic and biocompatible.

- Maintenance of a moist environment around the wound.

- Permits diffusion of the gases.

- Prevents saturation of dressing by removing exudates.

- Cost effective and cosmetically applicable.

Alginate based smart textile wound dressings: Alginates are defining as block copolymers containing two hexuronic acid residues, beta-D-mannuronic and alpha-L-glucoronic acid with exclusively 1-4 glycosidic linkage. Alginate based dressings are gaining popularity in wound management nowadays. They can form gels in presence of divalent cations like calcium. These calcium alginate fibers present in the dressing when comes in contact with the fluid, they are partly converted into water soluble sodium alginate. This then swells to form calcium sodium alginate gel surrounding the wound which keeps the wound moist and facilitates better healing. Some of the commercial alginate dressing products are Restore CalciCare by Hollister, Sorbsan by Berteck Pharmaceuticals, etc. Alginate dressings are preferred for slightly contaminated wounds and cavities but unsatisfactory in presence of dry necrotic tissue because there are no exudates present and hence there is no activation of alginates [35].

Hydrocolloids based smart textile wound dressings: Hydrocolloids are a multi-layered structure that comprises an outer layer which proved protection and a supporting material which is present in a form of fiber, film or coat. Hydrocolloid based dressings heal the wound by providing occlusion. The supporting materials sued are usually non-woven polyester fibers or semi-permeable polyurethane films. The hydrophilic component of the adhesive contains gelatine, polysaccharides, polyurethane gels, etc. These dressings interact with the wound exudates and form a hydrated gel on the wound surface. This gel is separated during dressing removal, there-fore, avoiding any harm to the newly formed skin. Commercially available products are Comfeel Ulcer Care Dressing by Coloplast, Tegasorb by $3 \mathrm{M}$ Healthcare. Hydrocolloids absorb the exudates and help to debride the wound. Hydrocolloids are suitable in presence of necrotic material [35]

Chitosan treated smart textile wound dressings: Chitosan is nontoxic, biocompatible and biodegradable. It is anti-microbial and inhibits the growth of wide species of yeasts, fungi and bacteria. It provides a $3 \mathrm{D}$ matrix that is non-protein in nature for tissue growth and activates macrophages for tumoricidal activity. It stimulates histoarchitecture's tissue organization and cell proliferation. It reduces pain by blocking nerve endings and enhancing natural blood clotting and acts like a hemostat. It facilitates faster healing and has greater chances of scar prevention. Some of the commercially available chitosan based products are HemCon badage and Trombogard [37].

The different kinds of chitosan treated wound dressings used in wound care management are [37]:

1. Cotton yarn/gauze fabrics treated with chitosan polymers.

2. Chitosan wound dressings prepared by Electrospinning method.

3. Chitosan films for wound care applications.

4. Chitosan treated wound dressings for drug delivery.

5. For wound care system, chitosan sponges, composite wound dressings/non-woven wound dressings.

Nanofibre based smart dressings (NFD) for burn wounds: Burn injuries are one of the crucial global healthcare issues. According to World Health Organization (WHO), every year 195000 people die because of fire. Moreover, people who survive burn injuries carry a stigma for lifetime deformities and disabilities [40].

\section{Wounds are classified based on their:}

1. Severity: the injuries can be major moderate or minor dependent upon factors such as total body surface area burnt, age and comorbidities.

2. Surface area: for determination of the burnt area, the rule of nines is applied.

3. Depth: they are divided into first, second, third and fourth degree burns.

Due to scarcity of cell mediated immunity and skin injury, the burn wounds are prone to microbial infections and hence should be protected. They are caused due to fungi and bacteria such as methicillinresistant Staphylococcus aureus (MRSA) and Pseudomonas aeruginosa. These bacteria secrete various proteases and damage adherent tissues. NFDs function in moist environment, do not need frequent changing and reduce pain and scars that is very beneficial for burn victims [40].

Various NFD based burn wound dressings are as follows:

1. Chitosan-coated PVA Nano-fibres for wound dressing.

2. Hyper branched polyglycerol (HPGL) NFD as delivery vehicle. 
3. Silicon dioxide NFD with embedded silver nanoparticles as recoverable wound cover. zein.

4. Degradation of collagen can be reduced by combining it with

5. Nano zinc oxide in combination with sodium alginate/PVA nanofibers to enhance antibacterial property.

6. Sustained release of dual drugs with composite nanofibers incorporated with drug loaded nanoparticles.

Although NFDs are effective as compared to conventional dressings they are expensive. Some of the commercially available NFD based wound dressings are Tegaderm, Integra, Biobrane and Transcyte [41]. They are extremely delicate and hence difficult to handle. Much more modifications can be expected in near future.

\section{Plasma modified textiles incorporated with silver ions for enhancing antimicrobial properties}

Non-thermal plasma technology changes the surface properties of polymer films as well as material characteristics like printability, adhesion, dyeing, etc. of complex substrates [42].

The most effective technique in inhibiting the attachment and growth of Gram positive and Gram-negative bacteria is controlled and sustained release of silver particles [37]. Non-thermal plasma increases wettability and roughness of textile substrate to enhance the uptake of silver nanoparticles or plasma polymer coating with controlled release properties. It shows bactericidal activity of more than $99 \%$.

Hence, it is safe to conclude that the incorporation of silver particles is the golden standard for producing anti-bacterial textiles. Non-thermal plasma technology is useful for immobilization of metal particles and plasma deposited coatings which enhance con-trolled release [43]. Commercially available product is Silvadur [44].

\section{Smart bandages}

There are a wide variety of bandages available and are used for various purposes like orthopedic applications for developments are taking place in smart bandages. The idea behind the concept is that they can simultaneously monitor the wound and indicate a signal in case of any irregularity or infection [45].

\section{Medical textile implantable devices}

Implantable are defined as the materials used in internal body parts for the purpose of healing or repairing internal wounds like surgical stitching of the wound during surgery [9]. The textiles used for implantable devices should be non-toxic, biocompatible and biodegradable wherever applicable. Non-biodegradable implants like ceramics, steel, carbons, titanium, silicones, etc. are meant to remain in the body for life [46]. Some of the major materials used in textile medical implants are given in Table 1 [47]. are [48]:

Some of the commercially available textile based medical implants

1. Artificial eye lenses (pseudophakos)

2. Ear tubes (tympanostomy tubes)

3. Coronary stents

4. Artificial knees

5. IUDs

\begin{tabular}{|c|c|c|}
\hline Applications & Materials & Textile structure \\
\hline Artificial skin & Chitin & Non-woven \\
\hline Oesophagus & Collagen & Multifilament \\
\hline Artificial tendon & $\begin{array}{l}\text { Polyester kelvar/ low-density } \\
\text { filaments }\end{array}$ & Woven \\
\hline $\begin{array}{l}\text { Haunch/breech } \\
\text { regeneration }\end{array}$ & Polypropylene-monofilament & Knitted \\
\hline Artery & Polyester Teflon/texture & $\begin{array}{l}\text { Knitted, woven, non- } \\
\text { woven }\end{array}$ \\
\hline Heart valves & Polyester multifilament & Knitted, woven-2D \\
\hline Vascular grafts & Polyester PTFE- multifilament & Warp knit \\
\hline Sutures & $\begin{array}{c}\text { Polyester, nylon, silk, collagen/ } \\
\text { mono/multifilament }\end{array}$ & Braided-woven \\
\hline Artificial bone & $\begin{array}{c}\text { Carbon, polyacetals, } \\
\text { polyethylene/ multifilament }\end{array}$ & Braided-woven \\
\hline Artificial ligament & $\begin{array}{c}\text { Polyester, silk, PTFE, } \\
\text { polyethylene/multifilament }\end{array}$ & Braided-woven \\
\hline
\end{tabular}

Table 1: Materials used for textile medical implants.

6. Breast implants

7. Heart pacemakers

8. Artificial hips

9. Implantable cardioverter defibrillators

10. Artificial heart valves

11. Artificial vascular grafts

12. Artificial tendon

13. Artificial ligaments

14. Artificial skin

15. Artificial heart, kidneys andlungs

\section{Healthcare products}

Textiles used for healthcare products should be biocompatible, should have air permeability, good dimensional stability, good resistance to alkalis, acids and microorganisms, elastic and good absorption and repellence properties [9].

- Cotton, polyester, polypropylene is used for making surgical gowns.

- Viscose and polyester are used for making surgical masks.

- Surgical caps are made from viscose.

- Polyester and polyethylene are used for manufacturing surgical drapes and clothes.

- Cotton and polyamide are used for surgical hosiery.

- Cotton and polyester are used for making blankets, sheets, pillows, uniforms and other protective clothing.

- Viscose and lyocell are also used for making clothes and wipes.

\section{Results, Discussion and Conclusion}

Today, the textile materials are addressing far more fundamental problems than expected. The textile materials are considered to be imperative ingredients of biological assemblies. Intricacy in design, complexity and function efficiency in performance are the key features of these new outlooks and will keep many researchers busy for now. With the healthcare sector transforming healthcare 1.0 to healthcare 
3.0, the healthcare segments are becoming more niche and selective in terms of defining their target market. This in turn is resulting into selective and targeted R\&D investment. With the textile industry and technological advancements progressing at a rapid rate, there is huge potential of innovation in this sector. It will attract more funds for $\mathrm{R} \& \mathrm{D}$ activities in foreseeable future.

In spite of significant amount and qualitative and quantitative innovation in medical textiles, this sector is still at a nascent stage. Medical textile market has better stakes of being sustainable in coming years in terms of commercialization and has a huge untapped potential yet to be discovered and explored.

\section{References}

1. Ahmed D (2009) Hybridization of smart textiles in medical and healthcare management. In: Proceeding of the AUTEX 2009 World Textile Conference, Izmir, Turkey, pp: 26-28.

2. Hiller L (1927) Sutures in ancient surgery. Brooklyn, NY: Davis and Geck, 1938.

3. Sekar N (1999) Single-stage preparatory processes for cotton: An update. Colourage, 46: 31-32.

4. Woodings C (2001) Regenerated cellulose fibres. Woodhead Publishing

5. Carroll-Porczynski CZ (1960) Manual of man-made fibres: manufacture, properties, identification, bibliography. Astex Pub Co.

6. Hamouda H (2005) Thermal Protective Clothing. Handbook of Environmental Degradation of Materials, 261.

7. Dijcker R, Van Der Wijk M, Artières O, Dortland G, Lostumbo J (2011) Geotextile enabled smart monitoring solutions for safe and effective management of tailings and waste sites: Two case studies: Volgermeerpolder (The Netherlands) and Suncor (Canada).

8. Rajendran S, Anand S (2014) High performance textiles for wound care. High Performance Textiles and Their Applications, 190.

9. Dorugade DV (2015) Medical textile. International journal on Textile Engineering and Processes.

10. Stoppa M, Chiolerio A (2014) Wearable electronics and smart textiles: A Critical Review. Sensors 11957-11992.

11. Shah TH (2009) Advances in technical textiles: Smart and intelligent textiles. Second International Technical Conference. Karachi, Pakistan: Pegasus.

12. Tao X (2001) Smart Technology for textiles and clothing-introduction and overview. In: Smart fibers, fabrics and clothing. Woodhead Publishing, Cambridge, UK, pp: 2-6.

13. Van Langenhove L, Hertleer C (2004) Smart clothing: A new life. International journal of clothing science and technology, 16: 63-72.

14. Perera WR (2008) Highly Conducting microfibers for wearable electronics. 86th Textile Institute World Conference. Honkong.

15. El-Sherif M (2005) Integration of fibre optic sensors and sensing networks into textile structures. Wearable Electronics and Photonics. Woodhead, Cambridge, pp: 105-135.

16. Mecnika V, Hoerr M, Krievins I, Schwarz A (2014) Smart textiles for healthcare: Applications and technologies. In: Rural Environment, Education and Personality (REEP). Proceedings of the International Scientific Conference (Latvia). Latvia University of Agriculture.

17. Sawhney APS, Condon B, Singh KV, Pang SS, Li G, et al. (2008) Modern applications of nanotechnology in textiles. Textile Research Journal 78: 731-739.

18. Jaskari T, Vuorio M, Kontturi K, Urtti A, Manzanares JA, et al. (2000) Controlled transdermal iontophoresis by ion-exchange fiber. Journal of Controlled Release 67: 179-190.

19. Breteler MT, Nierstrasz VA, Warmoeskerken MMCG (2002) Textile slow release systems with medical applications. Autex Research Journal 2: 175-189.

20. Loftsson T, Brewster ME (1996) Pharmaceutical applications of cyclodextrins. Pharm Sci 85: 1017-1025.

21. Bushmann DK (2001) Cyclodextrin. Inclusion Phenom Macro Chem 169-172.
22. Bradshaw I (1993) Hetrocylic compounds. New York: John Wiley and Sons.

23. Murthy CN, Geckeler KE (2001) The water soluble beta-cyclodextrin-[60] fullerene complex. Chem Comm 13: 1194-1195.

24. Ostad SN, Malhi JS, Gard PR (1998) In vitro cytotoxicity and teratogenicity of norethisterone and levonorgestrel released from hollow nylon monofilaments. J Control Release 50: 179-186.

25. Anand V, Kandarapu R, Garg S (2001) lon-exchange resins: Carrying drug delivery forward. Drug Discov Today 6: 905-914.

26. Lymberis A, Olsson S (2003) Intelligent biomedical clothing for personal health and disease management: State of the art and future vision. Elemed $\mathrm{J} E$ Health 9: 379-386.

27. Sibinski M, Jakubowska M, Sloma M (2010) Flexible temperature sensors on fibers. Sensors 10: 7934-7946.

28. Lee B (2003) Review of the present status of optical fiber sensors. Optical Fiber Technology 9: 57-79.

29. Krebber K (2013) Smart technical textiles based on fiber optic sensors. In Current Developments in Optical Fiber Technology, InTech.

30. Massaroni C, Saccomandi P, Schena E (2015) Medical smart textiles based on fiber optic technology: An overview. Journal of Functional Biomaterials 6: 204-221.

31. Karaguzel B, Merritt CR, Kang T, Wilson JM, Nagle HT, et al. (2009) Flexible, durable printed electrical circuits. The Journal of the Textile Institute 100: 1-9.

32. Pacelli M, Loriga G, Taccini N, Paradiso R (2006) Sensing fabrics for monitoring physiological and biomechanical variables: E-textile solutions. In Medical Devices and Biosensors, 2006. 3rd IEEE/EMBS International Summer School on IEEE, pp: 1-4.

33. Cherenack K, van Pieterson L (2012) Smart textiles: Challenges and opportunities. J Appl Phys 112: 091301.

34. Van Langenhove (2007) Textiles for protection. Wood-heads Publishing Cambridge, UK.

35. Gupta B, Agarwal R, Alam MS (2010) Textile-based smart wound dressings IJFTR 174-187.

36. Clark RA (1985) Cutaneous tissue repair: Basic biologic considerations. I J Am Acad Dermatol 13: 701-725.

37. Chellamani KP, Balaji RV, Sudharsan J (2013) Chitosan treated textile substrates for wound care applications. JAIR 2: 97.

38. Khan MN, Naqvi AH (2006) Antiseptics, iodine, povidone iodine and traumatic wound cleansing. J Tissue Viability 16: 6-10

39. Rajendran S, Anand SC (2006) Contribution of textiles to medical and healthcare products and developing innovative medical devices. Indian Journa of Fiber and Textile Research 215-229.

40. Nanowerk (2012) Medical Textiles: Nano-fibre based smart dressings for burn wounds.

41. Andreu V, Mendoza G, Arruebo M, Irusta S (2015) Smart dressings based on nanostructured fibers containing natural origin antimicrobial, anti-inflammatory, and regenerative compounds. Materials 8: 5154-5193.

42. Jacobs T, De Geyter N, Morent R, Van Vlierberghe S, Dubruel P, et al. (2011) Plasma modification of PET foils with different crystallinity. Surface and Coatings Technology 205: S511-S515.

43. Yao C, Li X, Neoh KG, Shi Z, Kang ET (2008) Surface modification and antibacterial activity of electrospun polyurethane fibrous membranes with quaternary ammonium moieties. Journal of Membrane Science 320: 259-267.

44. Morais DS, Guedes RM, Lopes MA (2016) Antimicrobial approaches for textiles: From research to market. Materials 9: 498.

45. Cools P, Morent R, De Geyter N (2016) Plasma modified textiles for biomedical applications.

46. Miraftab M (2014) High performance medical textiles: An overview. High Performance Textiles and Their Applications 176.

47. Scarlet R, Deliu R, Manea LR (2010) Implantable medical textiles Characterization and applications. In $7^{\text {th }}$ International Conference-TEXSCI Librec, Czech Republic.

48. Annapoorani SG (2013) Recent Developments in Medical Textiles Implantable Devices-An overview. Global Research Analysis 2: 255-258. 